\title{
Axial-flow-induced vibration experiments on cantilevered rods for nuclear reactor applications
}

DOI:

10.1016/j.nucengdes.2018.08.010

\section{Document Version}

Accepted author manuscript

Link to publication record in Manchester Research Explorer

\section{Citation for published version (APA):}

Cioncolini, A., Silva Leon, J., Cooper, D., Quinn, M., \& lacovides, H. (2018). Axial-flow-induced vibration experiments on cantilevered rods for nuclear reactor applications. Nuclear Engineering and Design, 338, 102-118. https://doi.org/10.1016/j.nucengdes.2018.08.010

\section{Published in:}

Nuclear Engineering and Design

\section{Citing this paper}

Please note that where the full-text provided on Manchester Research Explorer is the Author Accepted Manuscript or Proof version this may differ from the final Published version. If citing, it is advised that you check and use the publisher's definitive version.

\section{General rights}

Copyright and moral rights for the publications made accessible in the Research Explorer are retained by the authors and/or other copyright owners and it is a condition of accessing publications that users recognise and abide by the legal requirements associated with these rights.

\section{Takedown policy}

If you believe that this document breaches copyright please refer to the University of Manchester's Takedown Procedures [http://man.ac.uk/04Y6Bo] or contact uml.scholarlycommunications@manchester.ac.uk providing relevant details, so we can investigate your claim.

\section{OPEN ACCESS}




\title{
Axial-flow-induced vibration experiments on cantilevered rods for nuclear reactor applications
}

\author{
Andrea Cioncolini ${ }^{\mathrm{a}}$; Jorge Silva-Leon ${ }^{\mathrm{a}, \mathrm{b}}$; Dennis Cooper ${ }^{\mathrm{a}}$; Mark Kenneth Quinn ${ }^{\mathrm{a}}$; Hector Iacovides ${ }^{\mathrm{a}}$ \\ ${ }^{a}$ School of Mechanical, Aerospace and Civil Engineering, University of Manchester, George Begg Building, \\ Sackville Street, M1 3BB Manchester, United Kingdom. \\ ${ }^{\mathrm{b}}$ Escuela Superior Politécnica del Litoral, ESPOL, Facultad de Ingenería en Mecánica y Ciencias de la \\ Producción, Campus Gustavo Galindo km 30.5 Vía Perimetral, P.O. Box 09-01-5863, Guayaquil, Ecuador.
}

Axial-flow-induced vibration has been experimentally investigated with clamped-free cantilevered cylindrical rods confined in a tube and subjected to axial water flow directed from the rod free-end towards the clamped end: a simplified configuration relevant for water-cooled nuclear reactor cores. Non-contact optical techniques have been used to simultaneously detect the rods vibration and the flow field around the vibrating rods free-end. The source of excitation is turbulent buffeting at low flow velocity, while a movement induced excitation component is present at large flow velocities. The rods flow-induced vibration consists of a fuzzy period-1 motion: a periodic (period-1) motion with a chaotic component that increases in relative importance as the flow velocity is increased. The experimental data provided here are particularly suited for numerical fluid-structure model development and benchmarking, as they combine a rich fluid-structure multi-physics interaction with a relatively simple configuration and include both the flow field and the mechanical response of the vibrating rods.

Keywords: Fluid-structure interaction; Flow-induced vibration; Cantilever rod; Axial flow; Benchmark experiments; Nuclear reactor. 


\section{Introduction}

Structural vibrations induced by axial flow in slender cylindrical structures are generally of small amplitude, and therefore of little concern in most practical applications. Notable exceptions are nuclear reactor cores and other systems composed of closely-spaced cylindrical elements exposed to axial flows. Even small amplitude vibrations can consequently result in impacting between adjacent cylinders or between cylindrical elements and supports, thus causing fretting wear, fatigue and eventually structural cracking and system failure. Fretting wear is in fact responsible for the majority of fuel leaks observed in water-cooled nuclear reactors. This highlights the importance of analyzing and predicting axial-flow-induced vibrations for the safe and profitable operation of nuclear power stations. In most cases of practical interest involving cylindrical structures in axial flow, the observed flow-induced vibrations are so-called subcritical vibrations: low-amplitude vibrations whose dominant frequency corresponds to the first mode of the cylinder (Païdoussis, 2014). Divergence and flutter have been observed but are generally of little practical concern, as the flow velocities required for the inception of divergence and flutter are much higher than those typical of most engineering applications. With subcritical vibrations, the source of excitation is typically turbulent buffeting, so that these flow-induced vibration problems are characterized as Extraneously-Induced Excitations (EIE), as turbulence is largely independent of the movement of the structure, or of the way the structure affects the flow field. Turbulence in the flow induces pressure fluctuations along the cylinder surface that are spatially and temporally not uniform, thus giving rise to a random lateral load on the cylinder surface that causes lateral motion and triggers the vibration. These pressure fluctuations are typically wide-band, so that the cylinder can extract energy from the flow at frequencies corresponding to its natural frequencies, with the first natural frequency typically being dominant. In nuclear fuel bundles, and similarly with other systems composed of closely spaced cylindrical elements, even small-amplitude vibrations can appreciably change the geometry of the flow passage and therefore affect the axial flow, thus adding a Movement-Induced source of Excitation (MIE) to the flow-induced vibration problem. The proximity of the fuel rods, and the relatively high density of the coolants used in nuclear applications, result in strong fluid coupling among different fuel rods, meaning that the vibration of one rod can propagate to the adjacent rods as well. Therefore, in nuclear reactor fuel bundles, as the fuel rods extract energy from the turbulent flow and vibrate, their movement affects the axial flow and adjacent rods influence each other through fluid coupling. These interactions result in a tightly coupled multi-body fluid-structure interaction problem, where the axial flow and the rod vibrations dynamically interact and affect each other. Secondary sources of rod excitation that add further complexity to these problems include: 1) far-field disturbances transmitted through 
the flow, such as pump noise and cavitation; 2) vibrational noise transmitted through the system support structures; 3 ) inlet conditions in the fuel assemblies and flow restructuring based on the design of the lower core support plate, debris bottom nozzle filters and lower plenum internals; 4) variation in distance among different fuel assemblies due to positioning; and 5) fuel rod bowing and side effects near the core edges.

Axial-flow-induced vibrations in nuclear reactor applications are currently investigated using coupled computational fluid dynamics (CFD) and structural dynamics (SD) simulations, as analytical modeling and purely experimental investigation alone are not feasible. Analytical modeling of axial-flow-induced vibrations is, in fact, hampered by the procurement of the detailed information needed as input to the models: fluctuating pressure fields are very difficult to characterize a priori, and far-field upstream effects are problem-specific and very challenging to incorporate. On the other hand, testing at prototypical nuclear reactor operating conditions is too expensive to rely on a purely experimental approach to address the problem. To be representative of reactor conditions, in fact, a test piece should include several fuel rods together with the spacer grids and support structures, and should replicate the inlet conditions that depend on the design of the lower core support plate, so that the generated data would be representative of one specific reactor core design. The high pressure and high temperature test rig required to run the experiments would be quite expensive to build and operate, and the high operating pressure and temperature would make the direct visualization of the flow very challenging, if at all possible. In coupled $\mathrm{CFD} / \mathrm{SD}$ simulations, a high-resolution $\mathrm{CFD}$ calculation provides the instantaneous pressure field and associated turbulent fluid force on the fuel rod surface, which is then used as input to SD simulations that yield the fuel rod motion. Large computational grids (several tens of million cells) and advanced turbulent models (large eddy simulation) are typically required to properly capture the intricate geometry of nuclear fuel bundles and faithfully reproduce instantaneous pressure fields and mechanical loads (Conner et al., 2010; Yan et al., 2011; Elmahdi et al., 2011; Zhang and Yu, 2011; Delafontain and Ricciardi, 2012; Bakosi et al., 2013; Christon et al., 2016).

It is evident that experimental data are essential to properly back up the development and validation of $\mathrm{CFD} / \mathrm{SD}$ simulations. However, most existing studies only focus on the mechanical vibration or on the flow field, while experimental investigations where the mechanical vibration and the flow field are simultaneously resolved are still missing. As already highlighted, the feedback of the rod vibration on the flow field can be significant in tightly packed nuclear reactor cores, and this effect is not yet properly captured in existing experimental studies. The present investigation was therefore conducted to specifically provide experimental data for the development and validation of $\mathrm{CFD} / \mathrm{SD}$ models where both the flow field and the structural response are simultaneously 
resolved. In particular, we have investigated flow-induced vibrations with a clamped-free cantilevered cylindrical rod confined in a tube and subjected to axial flow directed from the rod free-end towards the clamped-end. The geometry of this system is considerably simplified, as spacer grids are not included and the single-rod configuration eliminates multi-body effects. Notably, this configuration yields relatively large rod displacements even at moderate flow velocities, thus making the two-way coupling between the fluid and the structure quite strong. This makes the present data particularly suited for CFD/SD model development and benchmarking, as they combine a rich fluid-structure interaction with a relatively simple configuration. The present configuration is actually the simplest one we could conceive that still retains relevance for CFD/SD model development for nuclear applications. Data generated with more prototypical configurations are clearly invaluable: however, the experimental complexity and the computational burden associated with actually using such data makes simplified configurations such as the one tested here valuable for CFD/SD models benchmarking. In addition, cantilevered flexible slender cylinders in axial annular flow directed from the freeend towards the clamped-end have not been extensively investigated so far (Rinaldi and Païdoussis, 2012), so the present study is actually also relevant in this more fundamental respect.

\section{Experimental setup and methodology}

\subsection{Test piece and test rig description}

Schematic representations of the test piece and test rig are provided in Figs. 1 and 2. As can be seen in Fig. 1, the test piece comprises a vertical rod that is clamped at the top end and free at the bottom end, so as to realize a clamped-free cantilevered configuration, and a confining vertical tube. The test fluid is water and the flow enters at the bottom of the confining tube and exits at the top, so that the test piece configures a simple rod-in-tube design with an axial annular flow that is directed vertically upward from the rod free-end towards the fixed-end. The vibrating rod consists of a $8.8 \mathrm{~mm} / 10 \mathrm{~mm}$ nominal inner/outer diameter AISI 316 stainless steel circular tube (surface roughness: 2-3 $\mu \mathrm{m}$ ), while the confining tube is a circular AISI 316 stainless steel tube with $21 \mathrm{~mm}$ $/ 25 \mathrm{~mm}$ nominal inner/outer diameter, so that the hydraulic diameter of the annular gap between the confining tube and the vibrating rod is of $11.0 \mathrm{~mm}$. The confining tube is rigidly connected to a fixed frame and near the free-end of the rod it includes a matching diameter Perspex transparent insert for optical access (required for the optical detection of the rod movement and for the visualization of the flow field, as explained below). As is well known, cantilevers are very responsive to forcing at the free-end (Blevins, 2001). In the present case, the forcing at the free-end of the vibrating rod depends on the shape of the rod-end-piece facing the incoming flow, which 
affects the flow at the vicinity of the moving free-end of the rod, thus influencing the fluid-structure interaction. In order to generate a wider experimental dataset, two different rod-end-piece configurations have been used: a blunt end-piece more prone to induce flow separation, and a more streamlined end-piece of semispherical shape. A concentrated mass located at the free-end of a cantilever can have a significant effect on its vibration. In order to minimize any effects on the rod dynamics due to the local mass of the free-end, both end-pieces were made in lightweight aluminum (aluminum density: $2.74 \mathrm{~g} \mathrm{~cm}^{-3}$; total mass of the end-pieces: $2.1 \mathrm{~g}$ for the blunt-end piece and $2.8 \mathrm{~g}$ for the semispherical end-piece; surface roughness of end-pieces: $0.4-0.5 \mu \mathrm{m}$; dimensions provided in Table 1) so that they do not appreciably modify the linear mass density of the vibrating rods. A pictorial representation of the vibrating rods is included in Table 1, which also includes all relevant geometrical and mechanical parameters. In what follows, the vibrating rods with blunt end-piece and semispherical end-piece will be referred to as blunt-end rod and curved-end rod, respectively.

During the tests, the vibrating rods were filled with lead so as to mimic the loading of fuel pellets in nuclear fuel bundles. In particular, lead shot (lead density: $\left.11.34 \mathrm{~g} \mathrm{~cm}^{-3}\right)$ with variable diameter $(0.3-1.6 \mathrm{~mm})$ was used as this yields better packing (packing ratio: $84.6 \%$ ) and a filling density of $9.6 \mathrm{~g} \mathrm{~cm}^{-3}$ that closely approximates the density of about $10 \mathrm{~g} \mathrm{~cm}^{-3}$ of uranium dioxide pellets. As can be seen in Fig. 1, a flow straightener is located at the entrance to the confining tube to suppress secondary flows and produce an undistorted velocity profile upstream of the vibrating rod. In particular, the flow straightener is a tube bundle conditioner (12 tubes, $3.0 \mathrm{~mm}$ /5.0 mm inner/outer diameter, $45 \mathrm{~mm}$ long; horizontal cross-section drawing provided in Fig. 1) of in-house construction, designed according to ASME standards (Miller, 1996) to remove swirl and secondary flows with limited pressure drop penalty. To further reduce far-field upstream effects, we avoided any change in the tube cross sectional area upstream of the test piece. The elbow schematically depicted at the entrance to the test piece in Fig. 1 is a long radius 90-degree bend with bend radius to tube radius ratio of 24. The horizontal pipe that feeds the test piece between the valve (full-bore ball valve) and the long radius 90 -degree bend is $2.0 \mathrm{~m} \mathrm{long}$. The long radius 90 -degree bend at the entrance to the test piece, which was introduced due to space limitations in the laboratory, will surely induce a distortion of the velocity profile, and this is actually why the flow straightener was included in the first place: to minimize such distortion. As shown in Figs. 12-15 and discussed later on, the velocity profiles measured right upstream of the rod free-end are quite close to fully developed, indicating that the flow straightener is indeed effective at removing the flow non-uniformity. At the discharge, the test piece is connected to two symmetrically-routed outlet pipes via a union cross (Swagelok SS-25M0-4), which also holds the vibrating rod in place. The vertical plane of the outlet pipes is 
perpendicular to the vertical plane of the inlet bend. A symmetric two-pipe discharge, rather than a standard onepipe radial outlet, was used to avoid any localized cross-flow close to the rod fixed-end, which could have affected the rod dynamics. As shown in Fig. 1 and Table 1, the distance between the exit of the flow straightener and the vibrating rods fixed-end is $2.5 \mathrm{~m}$, while the length $L$ of the vibrating rods is $1.060 \mathrm{~m}$ for the blunt-end rod and $1.045 \mathrm{~m}$ for the curved-end rod. Apart from the minor difference in their length, the only difference between the two rods is the geometry of the free-end. The straight pipe length between the flow straightener and the free-end of the vibrating rods is therefore $1.440 \mathrm{~m}$ for the blunt-end rod and $1.455 \mathrm{~m}$ for the curved-end rod, corresponding to about 69 tube diameters.

The dimensions of the rods tested, as well as the hydraulic diameter of the annular channel between the confining tube and the vibrating rod, are quite close to those of actual nuclear fuel rods, and the lead filling closely approximates the loading due to the fuel pellets. This makes the present experiments relevant for watercooled nuclear reactor flow-induced vibration applications. The present configuration for the vibrating rods, with the free-end of the rods facing the incoming flow, has been selected because it yields relatively large rod displacements even at moderate flow velocities. This makes the experimental data presented here particularly suited for $\mathrm{CFD} / \mathrm{SD}$ models development and benchmarking, as they combine a relatively strong fluid-structure coupling with a particularly simple geometry. During the tests, the mass flux in the annular channel between the confining tube and the vibrating rod varied between $1.0110^{3}-3.4510^{3} \mathrm{~kg} \mathrm{~m}^{-2} \mathrm{~s}^{-1}$, corresponding to an average flow velocity of 1.01-3.45 $\mathrm{m} \mathrm{s}^{-1}$ and Reynolds number of $12.710^{3}-45.210^{3}$ (based on the annulus hydraulic diameter of $11.0 \mathrm{~mm}$ ). Corresponding nominal values for full-power operation of a representative water-cooled nuclear reactor system (a Westinghouse 4-loop PWR plant; Dahlheimer et al., 2006) are $3.3610^{3} \mathrm{~kg} \mathrm{~m}^{-2} \mathrm{~s}^{-1}$ for the mass flux, $4.75 \mathrm{~m} \mathrm{~s}^{-1}$ for the average flow velocity, and $51410^{3}$ for the Reynolds number (based on the reactor core fuel assembly sub-channels hydraulic diameter of $13.0 \mathrm{~mm}$ ). Therefore, the mass flux range covered in the present experiments is representative of nuclear reactor operating conditions. Due to the difference in water density and viscosity between ambient conditions and reactor operating conditions, and due to the slightly lower hydraulic diameter of the present test piece $(11.0 \mathrm{~mm})$ as compared to that of a nuclear reactor core (13.0 $\mathrm{mm}$ ), the maximum flow velocity achieved in the present experiment is about $30 \%$ lower while the Reynolds number is roughly one tenth of those corresponding to reactor prototypical operating conditions.

Notwithstanding these limitations, the experimental data presented here include the non-contact detection of the rod vibration and the visualization of flow field, and therefore remain useful for the development and validation of $\mathrm{CFD} / \mathrm{SD}$ numerical models. Nuclear fuel rods are supported by spacer grids over their length and therefore are 
not cantilevers, so the present test configuration is relevant for nuclear reactor applications, but clearly it is not a faithful replica of actual nuclear fuel rods. However, at a fundamental physical level the excitation mechanisms at play in our simplified test piece and in actual nuclear reactor fuel bundles are essentially the same:

Extraneously-Induced Excitation (EIE) via turbulent buffeting and Movement-Induced Excitation (MIE) via rod vibration, albeit the turbulence intensity is different due to the lower Reynolds number, and the rod movement is different due to the different structural configuration, and multi-body effects are absent in the single-rod test piece investigated here.

As shown in Fig. 2, the test piece is connected to a recirculating open loop system driven by a centrifugal pump (Clarke CBM240 multi-stage 4-impeller pump; rotational speed: $2800 \mathrm{rpm}$ ). The test fluid is water at low pressure (0.2-0.3 MPa) and close to ambient temperature (294-303 K), where the slight variation of the water temperature is due to viscous heating in the pump. Water density and viscosity are calculated using NIST-REFPROP. The mass flow rate is measured with an in-house designed hydraulic resistance meter (accuracy within $\pm 2 \%$ ), while the temperature of the flowing water is measured with a direct immersion digital thermometer (ETI-Electronic Temperature Measurements Ltd; Direct immersion aquarium thermometer; temperature span: 248-343 K; accuracy within $\pm 1 \mathrm{~K}$ ).

\subsection{Rod vibration detection and flow field visualization}

The flow-induced motion of the free-end of the vibrating rods is recorded with a fast-imaging camera (Panasonic Lumix DMC-FZ200, recording frequency: 200 frames per second, resolution: 480x640 pixels, recording duration: $3 \mathrm{~min}$ ) positioned facing the test piece as schematically indicated in Fig. 1 (Camera 1). The movement of the vibrating rods is three-dimensional with no apparent dependence on the angle of observation around the test piece, as verified during preliminary tests where the camera was rotated around the test piece. The fastimaging camera was therefore located in the same position during all tests, and the observed plane motion is considered representative of the three-dimensional dynamics of the vibrating rods. We used the image processing toolbox of MATLAB to extract from the recorded videos the time series of the vibrating rod free-end displacement versus time. In particular, the error in the rod free-end displacement is estimated from the resolution of the recorded videos to be on the order of $\pm 10 \mu \mathrm{m}$.

We analyzed the rod displacement time-series using standard techniques (power spectrum, histogram, and autocorrelation function) and also using phase-space techniques specifically designed for nonlinear dynamical systems, a recent approach successfully applied to fluid-structure interaction problems with flexible structures 
(Ait Abderrahmane et al., 2011, 2012; Silva-Leon et al., 2018). In particular, we used the delayed vectors method (Bradley and Kantz, 2015) to reconstruct the system attractor in phase-space, whose topology provides useful qualitative characteristics of the vibrating rods dynamics that complete and corroborate the information obtained with standard time-series analysis techniques. The concept of phase-space representation, rather than a classic analysis in time or frequency domain, is the key point in nonlinear time-series analysis. The topology of the trajectory in phase-space of a nonlinear system, in fact, provides important information regarding the fundamental dynamics of the systems being investigated. The problem is that in experimental studies one normally observes a time-series of scalar measurements of some quantity that depends on the current state of the system, and not the trajectory of the system in phase-space. The delayed vectors method allows reconstructing the trajectory of the system in phase-space from a time-series of scalar measurements, and can therefore be used in experimental studies such as the present one where only time-series of scalar measurements of some quantity (the rod displacement here) are available. As shown later on, the rod displacement time-series are characterized by a strong periodic component, so that a good value of the delay needed as input to the delayed vectors methods is one quarter of the period (Kantz and Schreiber, 2004), corresponding to about $65 \mathrm{~ms}$ in the present case (13 frames in the videos acquired at $200 \mathrm{fps}$ ). Prior to the analysis, the rod displacement time-series were smoothed with a 23-point Henderson (Henderson, 1916) moving-average filter to remove noise. Moving-average filters are normally the preferred choice for noise reduction with time-domain encoded signals (Smith, 2003), and the 23point Henderson filter proved to be best among the various moving-average filters we investigated with the present dataset (lowest noise-to-signal RMS ratio). Notwithstanding their good noise reduction performance in the time domain, moving-average filters are poor low-pass filters in the frequency domain (Smith, 2003). For this reason, in the analysis that follows the displacement histogram, the autocorrelation function and the system trajectory in phase-space are based on the filtered displacement time-series, whereas the power spectra are estimated from the raw displacement time-series with the Welch's method (Welch, 1967) using MATLAB builtin functions.

The flow has been measured using a two-dimensional LaVision Particle Image Velocimetry (PIV) system consisting of an imager SX 4M CCD camera positioned facing the test piece as schematically indicated in Fig. 1 (Camera 2), imaging the flow with a MVL7000 18-108 mm lens providing an effective focal length of $500 \mathrm{~mm}$. The flow was illuminated using a Litron Nano TRL $200 \mathrm{~mJ}$ per pulse laser with pulse duration of approximately $6 \mathrm{~ns}$, and $100 \mathrm{~ms}$ time interval between successive pulses. The laser was coupled to an articulated light arm with a beam-width-controlling optic and a divergent lens providing a two-dimensional vertical laser sheet across the 
center plane of the flow field. The laser sheet followed a Gaussian profile with a FWHM (full width at half maximum) of $1 \mathrm{~mm}$ at the waist. Given the small width of the test section, the waist width can be considered the sheet width across the section. To visualize the flow, aluminum flakes (flat flakes of the type used in paints as metallic silver pigment with size of $5 \mu \mathrm{m}$ and concentration adjusted empirically to achieve the desired resolution) were added to the test water with a small amount of dispersant (1g of dispersant dissolved into 100 $\mathrm{kg}$ of test water, small enough to neglect effects on the water density or viscosity) to prevent flakes clumping. After adding the particles, the rig was left running on its highest flow rate for several minutes so as to circulate and evenly distribute the particles. As the flow is contained inside a cylindrical tube, it was necessary to build a surrounding box with flat faces so as to reduce the optical distortion via index matching. The surrounding box is realized using $10 \mathrm{~mm}$ thick Perspex (refractive index: 1.495 ), and has square cross-section with $100 \mathrm{~mm}$ side length. Filling this box with water (refractive index: 1.33) proved sufficient to remove the majority of the induced lensing effect of visualizing the flow through a cylindrical pipe. Calibrations have been performed using an in-house constructed calibration plate $(1 \mathrm{~mm}$ dots in square array spaced $2 \mathrm{~mm}$ apart $)$ that was placed inside the tube filled with stagnant water as shown in Fig. 3. The index-matching approach mentioned above proved successful such that there is very little distortion for the calibration to remove, as evidenced in Fig. 3, therefore the images are scaled based on the internal diameter of the pipe rather than a full intrinsic and extrinsic calibration. The scale of the images was $56.67 \mathrm{pixel} / \mathrm{mm}$ giving excellent spatial resolution. A representative PIV raw image for the curved-end rod is provided in Fig. 4.

\subsection{Validation of the experimental setup}

The test apparatus was validated with preliminary experiments of free vibration in still water. For these experiments, the test apparatus was flooded with static water and the rod free-end was manually displaced from equilibrium of about 2-3 mm, which is small enough to yield a first-mode cantilever vibration. The rod was then released and the vibration of the free-end was recorded and analyzed. As such, these validation tests correspond to free vibration experiments in still water and in confined geometry. A representative example of a free vibration test for the blunt-end rod is provided in Fig. 5, which includes: 1) a 5 s sample of the displacement time series (raw signal, filtered signal and noise); 2) the power spectrum of the time series; 3 ) the autocorrelation function of the time series; 4) the histogram of the time series ( 5 s sample; to help visualize the trend in the data, the histogram includes a red line corresponding to a normal density function fitted to the data); and 5) the system reconstructed attractor in phase space. As can be seen in Fig. 5, the rod free-end displacement is periodic with 
decreasing amplitude as time progresses, the power spectrum presents one dominant frequency $(3.7 \mathrm{~Hz})$, the autocorrelation function is periodic and slowly decaying, the displacement histogram is bridge-shaped and the trajectory of the system in phase-space is a converging spiral. All these features are characteristic of a damped periodic motion, as expected in the present case. Measured free vibration frequencies $f_{0}$, and damping ratios $\zeta_{0}$, of the vibrating rods are summarized in Table 2, together with the corresponding reference values $f_{\text {pred }}$ and $\zeta_{\text {pred. }}$. In particular, the natural vibration frequencies in Table 2 correspond to the dominant peak in the rod displacement power spectra, while the damping ratios are evaluated from the logarithmic decrement of the envelope of the displacement time series. The reference vibration frequencies $f_{\text {pred }}$ included in Table 2 correspond to cantilevered beam first-mode natural frequencies, and are predicted using standard Euler-Bernoulli beam theory as follows:

$$
f_{\text {pred }}=\frac{1.875^{2}}{2 \pi} \sqrt{\frac{E I}{m_{\text {tot }} L^{4}}}
$$

where $E I$ is the empty rod flexural rigidity (product of the Young modulus $E$ of the rod material times the moment of inertia $I$ of the cross sectional area of the rods; values provided in Table 1), computed without taking the lead filling into account, $L$ is the rod length while $m_{\text {tot }}$ is the total linear mass density of the rod:

$$
m_{\text {tot }}=m_{\text {rod }}+m_{\text {add }}
$$

where $m_{\text {rod }}$ is the linear mass density of the rod and accounts for the rod material and the shot lead filling (values provided in Table 1), while $m_{a d d}$ is the rod linear added mass density in confined water. This latter is estimated as follows (Blevins, 2001):

$$
m_{a d d}=\rho_{l} \frac{\pi}{4} d_{r o}^{2} \frac{1+\left(d_{r o} / D_{t i}\right)^{2}}{1-\left(d_{r o} / D_{t i}\right)^{2}}
$$

where $\rho_{l}$ is the test fluid density, $d_{r o}$ is the rod outer diameter and $D_{t i}$ is the confining tube inner diameter. As can be noticed in Table 2, the damping ratios of the vibrating rods are small enough to neglect the frequency shift induced by damping, which is therefore not included in Eq. (1). The reference damping ratios $\zeta_{\text {pred }}$ included in Table 2 correspond to fluid damping ratios for cylinders vibrating in a fluid-filled annulus, and are estimated as follows (Rogers et al., 1984; quoted in Blevins, 2001):

$$
\zeta_{\text {pred }}=\frac{\pi}{2 \sqrt{2}} \frac{\rho_{l} d_{r o}^{2}}{m_{\text {tot }}} \frac{1}{R e_{v}^{0.5}} \frac{1+\left(d_{\text {ro }} / D_{t i}\right)^{3}}{\left(1-\left(d_{r o} / D_{t i}\right)^{2}\right)^{2}}
$$

where $R e_{v}$ is the vibrational Reynolds number:

$$
R e_{v}=\frac{\pi}{2} \frac{\rho_{l} f d_{r o}^{2}}{\mu_{l}}
$$


while $f$ is the rod vibration frequency and $\mu_{l}$ is the test fluid viscosity. As discussed in Blevins (2001), Eqs. (3) and (4) are applicable to small vibrations where the ratio of vibration amplitude to rod diameter is within 0.2-0.3: a requirement that the present free vibration tests satisfy. As evident from inspecting Eqs. (3) and (4), the confinement of the tube that surrounds the rods increases both the added mass and the damping ratio of the vibrating rod, as compared to the corresponding unconfined configuration. In the present case the effect is considerable and is of about $60 \%$ for the added mass, and of about $85 \%$ for the damping ratio. As can be seen in Table 2, the agreement between measurements and predictions is rather good, thus validating the present experimental approach. In particular, as previously noted, the curved-end rod is slightly shorter (of about $1.4 \%$ ) than the blunt-end rod, and this is reflected in its natural vibration frequency that is slightly higher (of about $2.8 \%$ ) than that of the blunt-end rod.

\section{Results and discussion}

The response diagram for the vibrating rods is provided in Fig. 6 (top), where flow-induced vibration data are presented as reduced RMS displacement $A^{*}$ of the rods free-end versus reduced velocity $u^{*}$ :

$$
\begin{aligned}
& A^{*}=\frac{A_{R M S}}{d_{r o}} \\
& u^{*}=\frac{V}{f_{0} d_{r o}}
\end{aligned}
$$

where $A_{R M S}$ is the RMS displacement of the rod free-end, $V$ is the average flow velocity in the annulus between the vibrating rod and the confining tube while $f_{0}$ is the rod free vibration frequency in still water (from Table 2). Vibration frequencies $f$ corresponding to the dominant peaks in the rod displacement power spectra are provided in Fig. 6 (bottom) as a function of the reduced velocity. Additional plots of the reduced RMS displacements and vibration frequencies versus Reynolds number are presented in Fig. 7. For these additional plots, the Reynolds number for the flow in the annulus between the vibrating rod and the confining tube is calculated as follows:

$$
R e_{\text {ann }}=\frac{\rho_{l} V d_{h y d}}{\mu_{l}}
$$

where $d_{h y d}=D_{t i}-d_{r o}$ is the annulus hydraulic diameter, equal to $11.0 \mathrm{~mm}$ in the present case. If the tests were conducted with a constant temperature fluid, then the density and viscosity of the fluid would be constant and the Reynolds number in Eq. (8) would be exactly proportional to the reduced velocity in Eq. (7). In this case, the plots in Figs. 6 and 7 would look alike, apart from the different variable in the horizontal axis. Due to viscous heating in the pump, the temperature of the test fluid in the present experiments varied in the range 294-303 K, which is large enough to yield an appreciable variation of the fluid viscosity. This explains why the plots in Figs. 
6 and 7 look similar but are not identical. Following common practice in flow-induced vibration studies, the discussion that follows will be based on the response diagram and frequencies in Fig. 6, while the additional plots in Fig. 7 are included for completeness. As can be noted in Fig. 7, the Reynolds number values are large enough to yield fully turbulent flow conditions in all tests.

As can be seen in Fig. 6, the reduced RMS displacement of the rods increases when the reduced velocity is increased, while the rods vibration frequencies decrease when the reduced velocity is increased and their limiting values at low reduced velocities are comparable with the rods free vibration frequencies from Table 2 . In particular, it is evident in Fig. 6 (top) that for reduced velocities below about $u^{*} \approx 50$ the rate of increase of the reduced RMS displacement with reduced velocity is rather mild and the data points for the two rods collapse on the same trend line, thus indicating that the rod free-end has no effect on the rod vibration at these reduced velocities. On the other hand, for reduced velocities above about $u^{*} \approx 50$ the rate of increase of the reduced RMS displacement with reduced velocity is steeper and the data points for the two rods collapse on different trend lines, indicating that the rod free-end is now affecting the rod vibration. In particular, for a given reduced velocity the blunt-end rod yields larger reduced RMS displacements, as compared with the curved-end rod. These results can be qualitatively interpreted as follows. For reduced velocities below about $u^{*} \approx 50$ the rod vibration can be regarded as extraneously induced (EIE), and the main source of excitation is turbulent buffeting. The movement of the rods at these reduced velocities is too small to appreciably affect the flow, so that the excitation is caused by the turbulent fluctuations in the flow: turbulence induces pressure fluctuations along the rod surface that are spatially and temporally not uniform, thus yielding a fluctuating lateral load acting on the rod that triggers the rod vibration. Being a pressure force, the fluctuating lateral load at a given flow velocity essentially depends on the rods lateral surface area, which is comparable for the two rods, while it is not significantly affected by the geometry of the rod free-end: this explains why the two rods vibrate similarly at these reduced velocities. On the other hand, for reduced velocities above about $u^{*} \approx 50$ the movement of the rods becomes large enough to appreciably affect the flow field, so that a movement-induced source of excitation (MIE) now affects the rods vibration in addition to turbulent buffeting. In movement-induced excitations, the movement of the vibrating body perturbs the flow field and triggers a fluctuation in the fluid force acting on the vibrating body itself. The perturbation of the flow field clearly depends on the geometry of the rod free-end, which affects the flow development around the free-end of the rods: this explains why the two rods vibrate differently at these reduced velocities. The blunt-end piece, in particular, modifies the flow field more severely than the streamlined curved-end piece: this explains why at a given reduced velocity the blunt-end rod vibrates 
with larger reduced RMS displacements than the curved-end one. Regarding the mild reduction in rod vibration frequency observed in Fig. 6 (bottom) as the reduced velocity is gradually increased, this can be interpreted as the consequence of an increase in added mass and/or fluid damping due to the fluid flow. However, this effect is rather small and barely noticeable with the present experimental resolution. Notably, results qualitatively similar to those presented in Fig. 6 have been reported by Rinaldi and Païdoussis (2012), who tested a cantilever flexible tubular cylinder in confined axial air-flow.

Representative flow-induced vibration tests results for both vibrating rods at selected reduced velocities are provided in Figs. 8-11 and include: 1) a 5 s sample of the displacement time series (raw signal, filtered signal and noise); 2) the power spectrum of the time series; 3) the autocorrelation function of the time series; 4) the histogram of the time series (to help visualize the trend in the data, the histogram includes a red line corresponding to a normal density function fitted to the data); and 5) the system reconstructed attractor in phase space. In particular, Fig. 8 for the blunt-end $\operatorname{rod}\left(u^{*}: 35.7 ; R e_{a n n}: 16.410^{3}\right)$ and Fig. 9 for the curved-end rod $\left(u^{*}: 35.4 ; \operatorname{Re}_{\text {ann }}: 16.810^{3}\right)$ are representative of the rod dynamics at low reduced velocities below about $u^{*} \approx 50$; while Fig. 10 for the blunt-end $\operatorname{rod}\left(u^{*}: 83.5 ; R e_{a n n}: 35.110^{3}\right)$ and Fig. 11 for the curved-end rod $\left(u^{*}\right.$ : 83.1; $R e_{\text {ann }}: 36.410^{3}$ ) are representative of the rod dynamics at high reduced velocities above about $u^{*} \approx 50$. In the previous Figs. 6-7, the data points corresponding to the test conditions analyzed in Figs. 8-11 are indicated with arrows. As can be seen in Figs. 8-9, the power spectra representative of the rods dynamics at low reduced velocities present one dominant frequency, the autocorrelation functions are periodic and slowly decaying, and the displacement histograms are bridge-shaped, even though not perfectly symmetric as commonly observed with most real systems. These features are indicative of a rather periodic (period-1) motion. The trajectory of the system in phase-space, however, appears like a blob without the ring-like topology characteristic of periodic (period-1) motions, thus indicating that the rod motion contains a chaotic component. The rods vibration at low reduced velocities can therefore be regarded as a periodic (period-1) motion with a chaotic component, which is normally referred to as fuzzy period-1 motion (Païdoussis, 2014). Similar conclusions apply as well at high reduced velocities, as can be observed in Figs. 10-11: one dominant peak in the power spectra, periodic and rather slowly decaying autocorrelation function, though the decay appears now somewhat faster, and blob-like trajectory of the system in phase-space: all indicative of a fuzzy period-1 motion. The displacement histograms have now Gaussian-like distributions, which being typical of chaotic systems indicate a larger chaotic component in the rods motion at higher reduced velocities as compared to low reduced velocities. 
Representative flow visualization results for both vibrating rods are provided in Figs. 12-15 and include: 1) the velocity vector fields around the rods free-end; 2) the axial velocity profiles; and 3) the radial velocity profiles. In particular, Fig. 12 for the blunt-end rod $\left(u^{*}: 35.7 ; R e_{a n n}: 16.410^{3}\right)$ and Fig. 13 for the curved-end rod $\left(u^{*}\right.$ : 35.4; $R e_{a n n}: 16.810^{3}$ ) are representative of the rod dynamics at low reduced velocities below about $u^{*} \approx 50$, while Fig. 14 for the blunt-end rod $\left(u^{*}: 83.5 ; R e_{a n n}: 35.110^{3}\right)$ and Fig. 15 for the curved-end rod $\left(u^{*}: 83.1\right.$; $R e_{a n n}: 36.410^{3}$ ) are representative of the rod dynamics at high reduced velocities above about $u^{*} \approx 50$, and complete the data provided in Figs. 8-11 and previously discussed. Velocity profiles in Figs. 12-15 are provided at three different vertical elevations: 1$)$ upstream of the rods free-end ( 0.45 tube diameters, corresponding to 10 $\mathrm{mm}) ; 2$ ) in correspondence of the rods free-end; and 3$)$ downstream of the rods free-end ( 0.45 tube diameters, corresponding to $10 \mathrm{~mm}$ ). In particular, the velocity profiles extracted in correspondence of the rods free-end and downstream of the rods free-end have a vertical offset of 0.3 and 0.6 respectively added to better separate the profiles and make it easier to read the figures. All velocity data included in Figs. 12-15 are normalized with respect to the maximum upstream velocity $V_{-i n f}$, corresponding to the centerline velocity in the confining tube upstream of the rods free-end ( 0.45 tube diameters, corresponding to $10 \mathrm{~mm}$ ), and are specific for the system configuration where the vibrating rods are aligned in the center of the confining tube. The laser sheet used to visualize the flow was vertical and illuminated the vibrating rods from the right in Figs. 12-15: the region on the left of the rods was therefore not illuminated, and the local flow field was therefore not resolved.

Not surprisingly, as can be seen in Figs. 12-15, the stagnation point at the rod free-end and the flow acceleration around the rod free-end are more pronounced for the blunt-end rod, as compared with the curved-end rod that has a more streamlined free-end profile. This is also reflected in the velocity profiles, which are qualitatively comparable for the two rods but show more pronounced variations for the blunt-end rod. Interestingly, the velocity profiles measured upstream of the rods free-end show little departure from fully-developed pipe flow, indicating that the flow disturbance caused by the rod free-end is rather localized and does not extent for more than a few millimeters upstream of the rods free-end. They also indicate that the flow straightener placed at the entrance to the test piece is indeed effective at removing the flow non-uniformity due to the piping routing upstream of the test piece. Notably, there is no discernible flow detachment around the rods free-end, not even for the blunt-end rod, at least to within the experimental resolution of the present study. This is consistent with the large values of the reduced velocity explored in the present study, which was of about $u^{*} \approx 36$ for the tests in Figs. 12-13 and of about $u^{*} \approx 83$ for the tests in Figs. 14-15. As well known, the reduced velocity can be interpreted as a ratio of time scales as follows: 


$$
u^{*}=\frac{V}{f_{0} d_{r o}}=\frac{1 / f_{0}}{d_{r o} / V}=\frac{\tau_{s t}}{\tau_{f l}}
$$

where $\tau_{s t}$ is the time scale of the vibrating structure, while $\tau_{f l}$ is the time scale of the flow. A reduced velocity much bigger than 1, as in the present case, indicates a fluid-structure interaction problem where the time scale of the vibrating structure is much bigger than the time scale of the flow, so that the fluid changes much faster than the movement of the structure. Irrespective of the structural movement and the perturbation to the flow field that this induces, therefore, the flow has ample time to adapt to the movement of the vibrating rods, and can therefore remain attached to the rod free-end even when this is not streamlined. It is worth noting that the apparent absence of flow separation (to within the present experimental resolution) does not rule out the previously identified movement-induced excitation (MIE) at high reduced velocities. In fact, flow separation is not a necessary condition for MIE: it is sufficient that the movement of the rod is large enough to change the geometry of the flow passage and affect the flow. In the present case, RMS displacements reach as large as $300 \mu \mathrm{m}$ with maximum displacements above $500 \mu \mathrm{m}$ (as shown in Figs. 10-11): this is large enough to appreciably modify the geometry of the annular passage between the rod and the confining tube, making the annular passage asymmetric and thus affecting the flow.

The raw data (water mass flow rate, water temperature, rod rms displacement, and rod frequency) are provided as supplementary material, available in the online version of this paper.

\section{Conclusions}

Flow-induced vibrations with clamped-free cantilevered cylindrical rods confined in a tube and subjected to axial water flow directed from the rod free-end towards the clamped one have been investigated in this study. We tested two rods that differ in the geometry of the end-piece facing the incoming flow: a blunt-end rod, and a streamlined curved-end rod. Though considerably simplified, the geometry of this test system is representative of water-cooled nuclear reactors and yields relatively large rod displacements even at moderate flow velocities. We detected the vibration of the rods optically, and simultaneously measured the flow field around the rods freeend with PIV. This makes the present data particularly suited for CFD/SD models development and benchmarking, as they combine a rich fluid-structure interaction with a relatively simple configuration and include both the flow field and the mechanical response of the vibrating rods. The rods vibration was a fuzzy period-1 motion at all reduced velocities tested, which is characterized by a periodic (period-1) motion with a chaotic component that increases in relative importance as the reduced velocity is increased. The reduced RMS 
displacement of the rods increases with increasing reduced velocity, while the rods vibration frequency slightly decreases with increasing reduced velocity, though remaining quite close to the rods free vibration frequencies in still water. The source of excitation is turbulent buffeting at small reduced velocities, while a movement induced excitation component is present at large reduced velocities. The flow disturbance caused by the rod free-end is localized and does not extent for more than a few millimeters upstream of the rods free-end. Consistently with the large reduced velocities explored in the tests, no discernible flow detachment has been detected around the rods free-end, not even for the blunt-end rod.

\section{Acknowledgement}

The financial support from EDF-Energy is gratefully acknowledged.

\section{References}

Ait Abderrahmane, H., Paidoussis, M.P., Fayed, M., Ng, H.D., 2011. Flapping dynamics of a flexible filament. Phys. Rev. E 84, 066604.

Ait Abderrahmane, H., Paidoussis, M.P., Fayed, M., Ng, H.D., 2012. Nonlinear dynamics of silk and Mylar flags flapping in axial flow. J. Wind Eng. Ind. Aerodyn. 107-108, 225-236.

Bakosi, J., Christon, M.A., Lowrie, R.B., Protchett-Sheats, L.A., Nourgaliev, R.R., 2013. Large-eddy simulations of turbulent flow for grid-to-rod fretting in nuclear reactors. Nucl. Eng. Des. 262, 544-561.

Blevins, R.D., 2001. Flow-Induced Vibrations, second ed. Krieger Publishing Company, Malabar, USA.

Bradley, E., Kantz, H., 2015. Nonlinear time-series analysis revisited. Chaos 25, 097610.

Christon, M.A., Lu. R., Bakosi, J., Nadiga, B.T., Karoutas, Z., Berndt, M., 2016. Large-eddy simulation, fuel rod vibration and grid-to-rod fretting in pressurized water reactors. J. Comput. Phys. 322, 142-161. 
Conner, M.E., Baglietto, E., Elmahdi, A.M., 2010. CFD methodology and validation for single-phase flow in PWR fuel assemblies. Nucl. Eng. Des. 240, 2088-2095.

Dahlheimer, J.A. et al., 2006. The Westinghouse Pressurized Water Reactor Nuclear Power Plant. Westinghouse Electric Company LLC, USA.

Delafontain, S., Ricciardi, G., 2012. Fluctuating pressure calculation induced by axial flow through mixing grid. Nucl. Eng. Des. 242, 233-246.

Elmahdi, A.M., Lu, R., Conner, M.E., Karoutas, Z., Baglietto, E., 2011. Flow induced vibration forces on a fuel rod by LES CFD analysis. NURETH14-14 ${ }^{\text {th }}$ International Topical Meeting on Nuclear Reactor Thermal Hydraulics, Toronto, Canada.

Henderson, R., 1916. Note on graduation by adjusted average. Trans. American Soc. Actuaries 17, 43-48.

Kantz H., Schreiber, T., 2004. Nonlinear Time Series Analysis, second ed. Cambridge University Press, USA.

Miller, R.W., 1996. Flow Measurement Engineering Handbook, third ed. McGraw-Hill, USA.

Païdoussis, M.P., 2014. Fluid-Structure Interactions: Slender Structures and Axial Flow, second ed. Academic Press, Oxford, UK.

Rinaldi, S., Païdoussis, M.P., 2012. Theory and experiments on the dynamics of a free-clamped cylinder in confined axial air-flow. J. Fluid Struct. 28, 167-179.

Rogers, R.J., Taylor, C., Pettigrew, M.J., 1984. Fluid effects on multi-span heat exchanger tubes vibration, ASME-PVP Conference, San Antonio-Tx, USA.

Silva-Leon, J., Cioncolini, A., Filippone, A., Domingos, M., 2018. Flow-induced motions of flexible filaments hanging in cross-flow. Exp. Therm. Fluid. Sci. 97, 254-269. 
Smith, S.W., 2003. Digital Signal Processing, third ed. Newnes, Boston, USA.

Welch, P.D., 1967. The use of Fast Fourier Transform for the estimation of power spectra: A method based on time averaging over short, modified periodograms. IEEE Trans. Audio Electroacoustics 15, 70-73.

Yan, J., Yuan, K., Tatli, E., Karoutas, Z., 2011. A new method to predict grid-to-rod fretting wear in a PWR fuel assembly inlet region. Nucl. Eng. Des. 241, 2974-2982.

Zhang, X., Yu, S.D., 2011. Large eddy simulation of turbulent flow surrounding two simulated CANDU fuel bundles. Nucl. Eng. Des. 241, 3553-3572. 


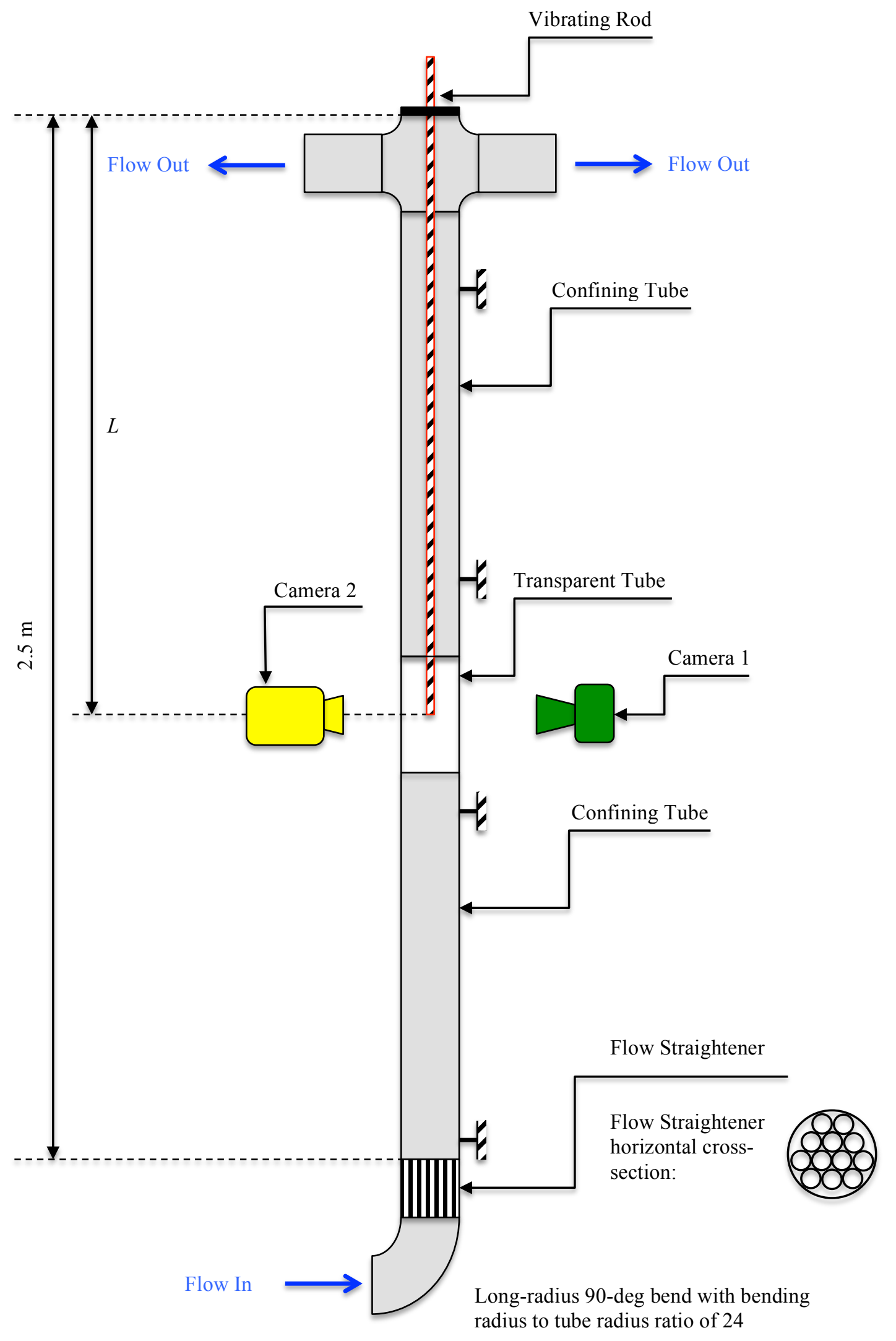

Fig. 1. Schematic representation of the test piece. 


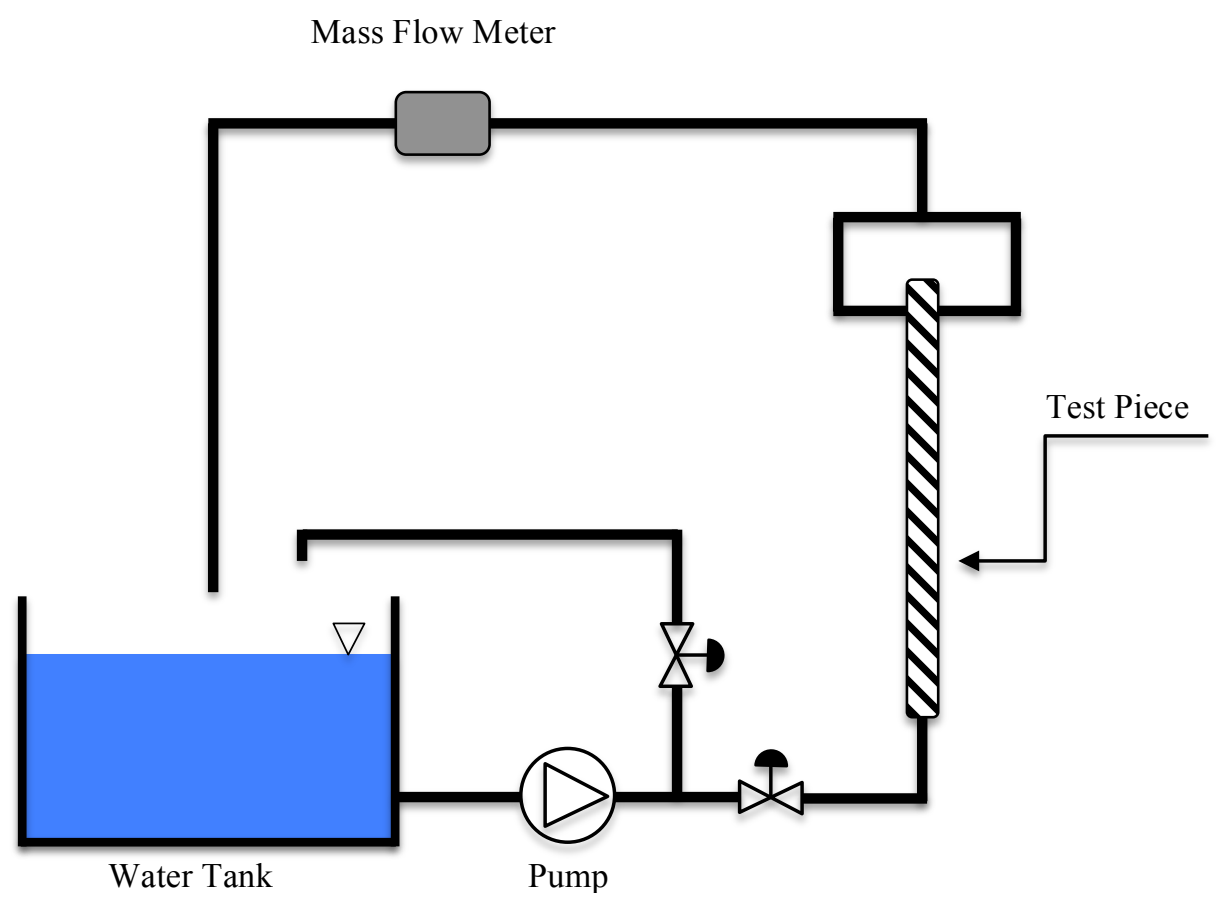

Fig. 2. Schematic representation of the test rig. 


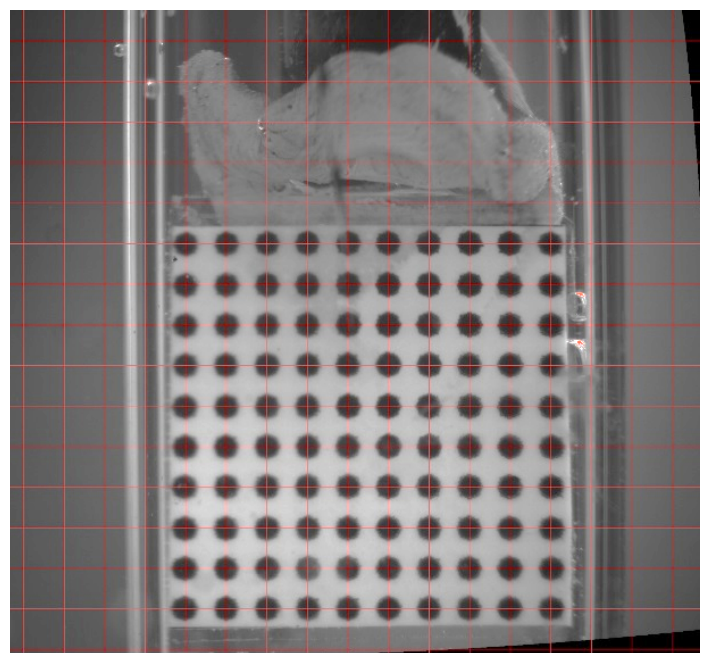

Fig. 3. Image of the in-house constructed calibration plate positioned inside the confining transparent tube filled with stagnant water after using index matching to reduce optical distortion. 


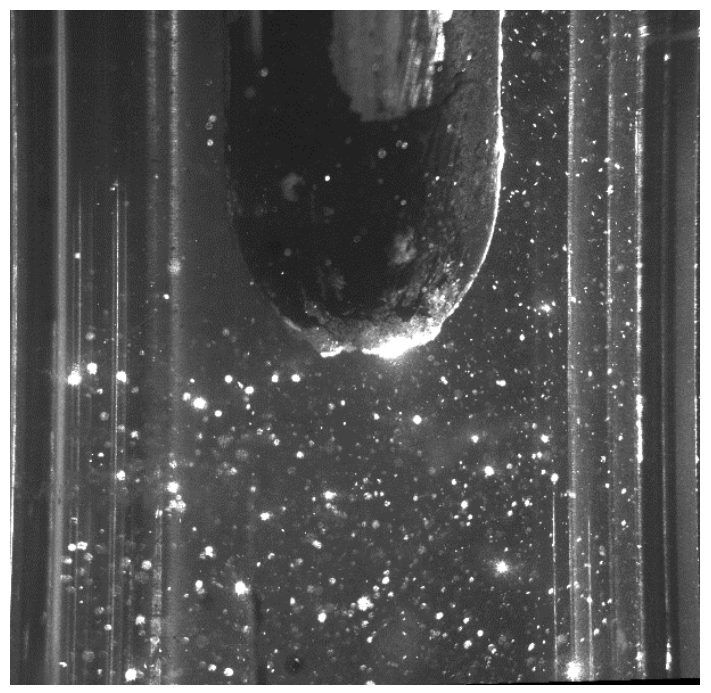

Fig. 4. Representative raw PIV image for the semispherical-end rod (the laser sheet is vertical and illuminates the test piece from the right). 

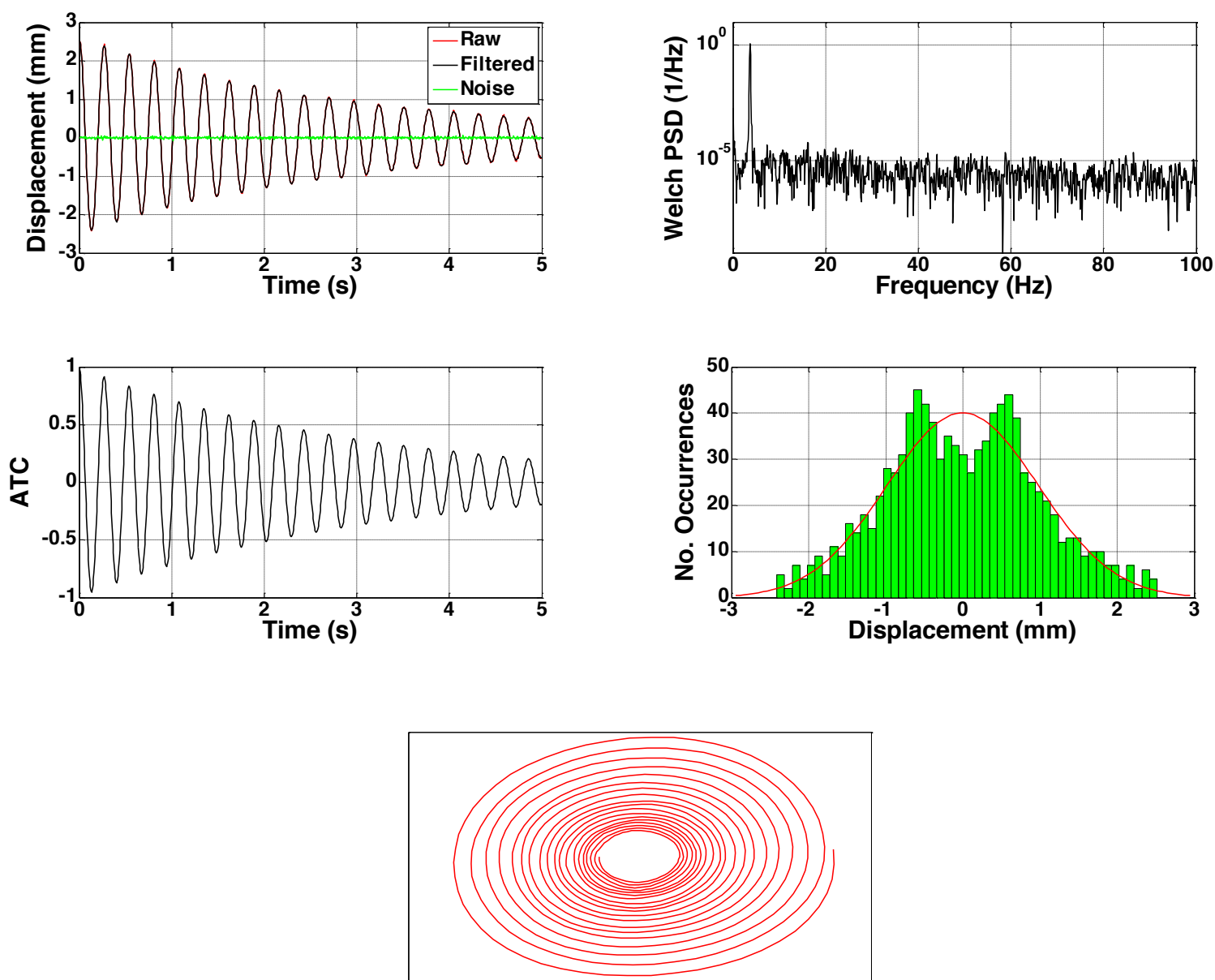

Fig. 5. Representative result for free vibration of the blunt-end rod in still water. Top-Left: free-end displacement time series ( $5 \mathrm{~s}$ sample); Top-right: free-end displacement power spectrum (PSD); Middle-left: free-end displacement autocorrelation function (ATC); Middle-right: free-end displacement histogram (5 s sample); Bottom: trajectory of the system in phase-space. 

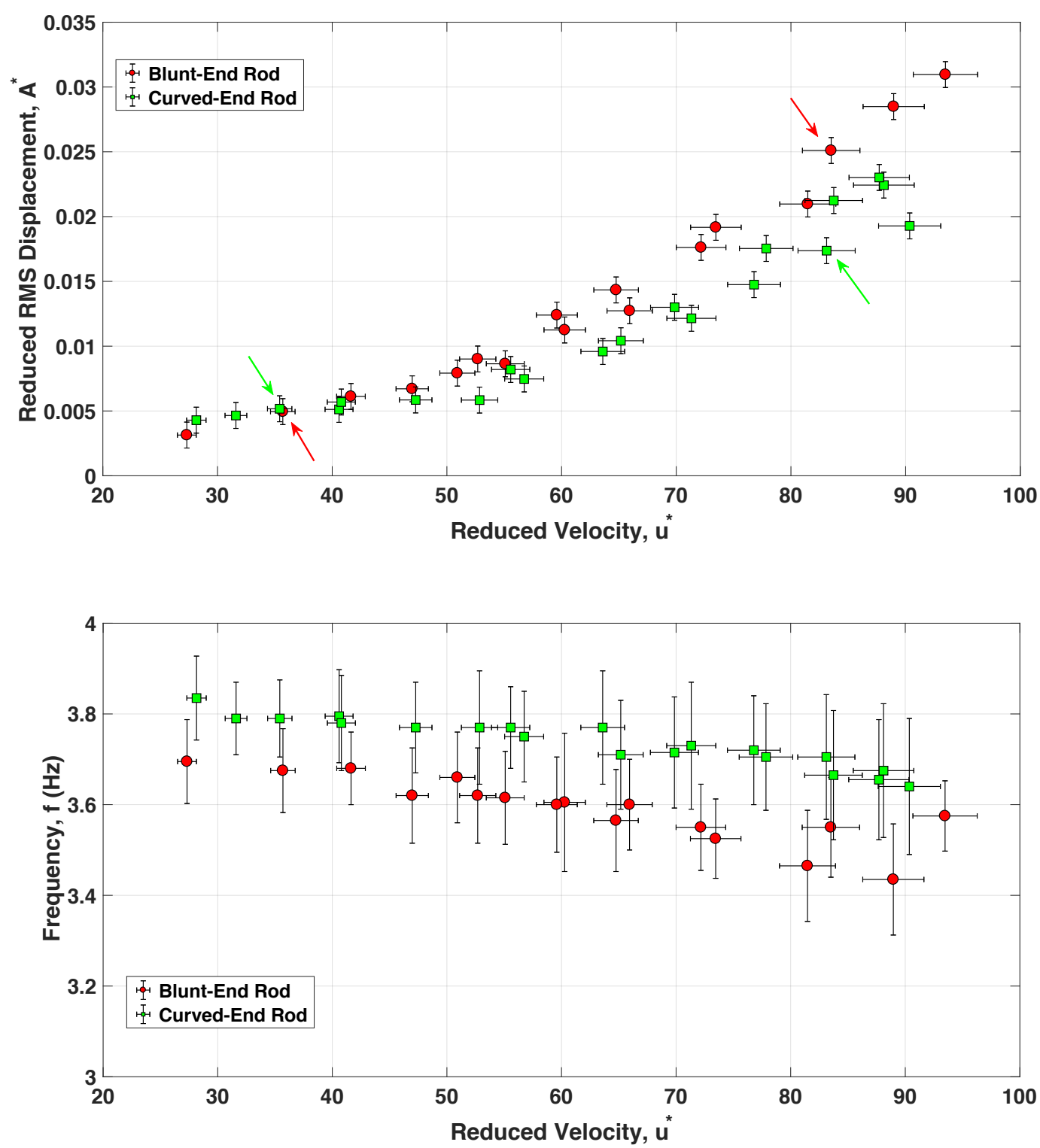

Fig. 6. Rods flow-induced vibration: reduced RMS displacement vs. reduced velocity (top), and frequency vs. reduced velocity (bottom). The arrows indicate the data points that are further analyzed in the Figs. 8-11. 

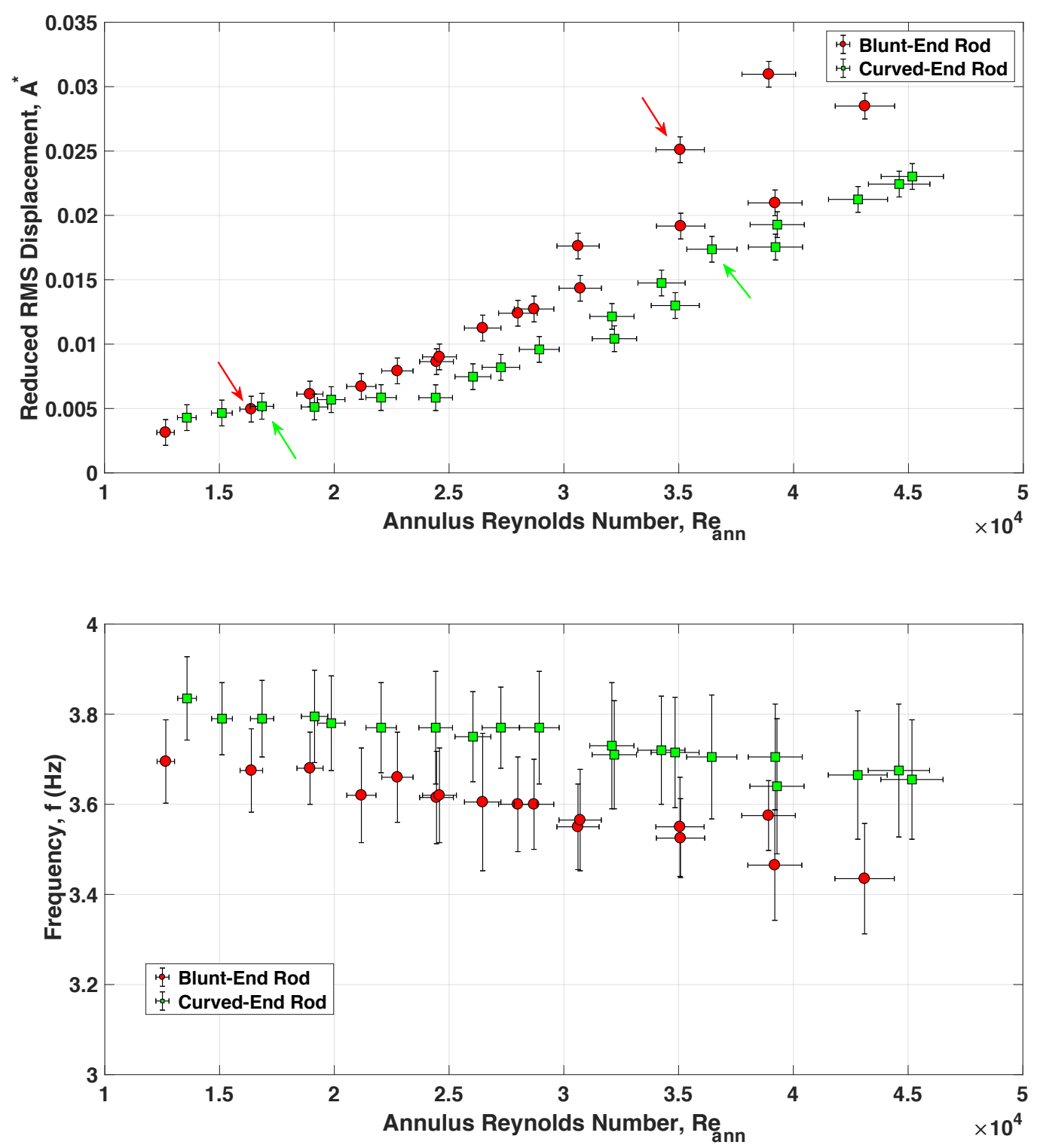

Fig. 7. Rods flow-induced vibration: reduced RMS displacement vs. annulus Reynolds number (top), and frequency vs. annulus Reynolds number (bottom). The arrows indicate the data points that are further analyzed in the Figs. 8-11. 

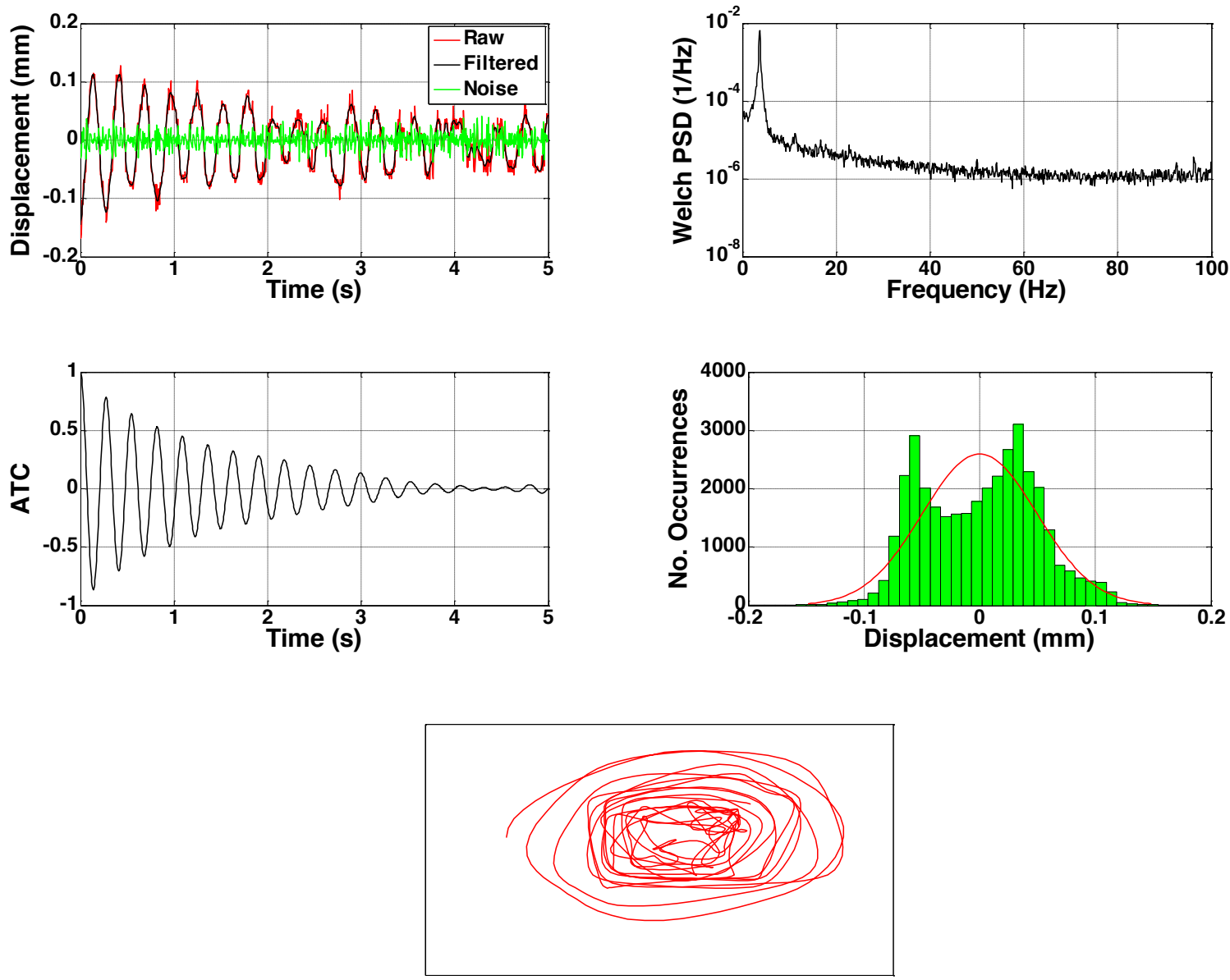

Fig. 8. Flow-induced vibration of the blunt-end rod at low flow velocity $\left(u^{*}: 35.7 ; R e_{a n n}: 16.410^{3}\right)$. Top-Left: free-end displacement time series (5 s sample); Top-right: free-end displacement power spectrum (PSD); Middle-left: free-end displacement autocorrelation function (ATC); Middle-right: free-end displacement histogram ( 5 s sample); Bottom: trajectory of the system in phase-space. 

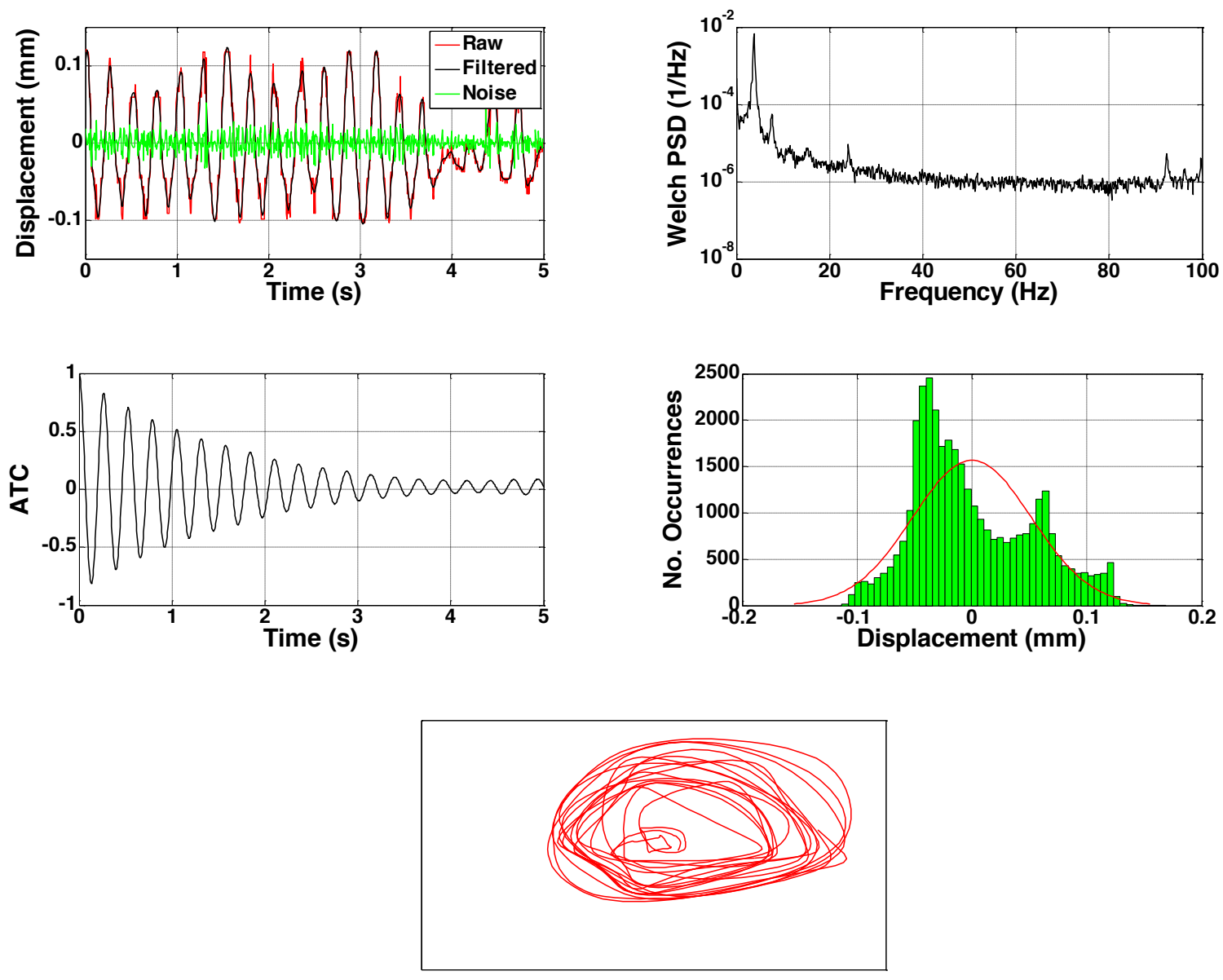

Fig. 9. Flow-induced vibration of the curved-end rod at low flow velocity $\left(u^{*}: 35.4 ; R e_{a n n}: 16.810^{3}\right)$. Top-Left: free-end displacement time series ( $5 \mathrm{~s}$ sample); Top-right: free-end displacement power spectrum (PSD); Middle-left: free-end displacement autocorrelation function (ATC); Middle-right: free-end displacement histogram ( $5 \mathrm{~s}$ sample); Bottom: trajectory of the system in phase-space. 

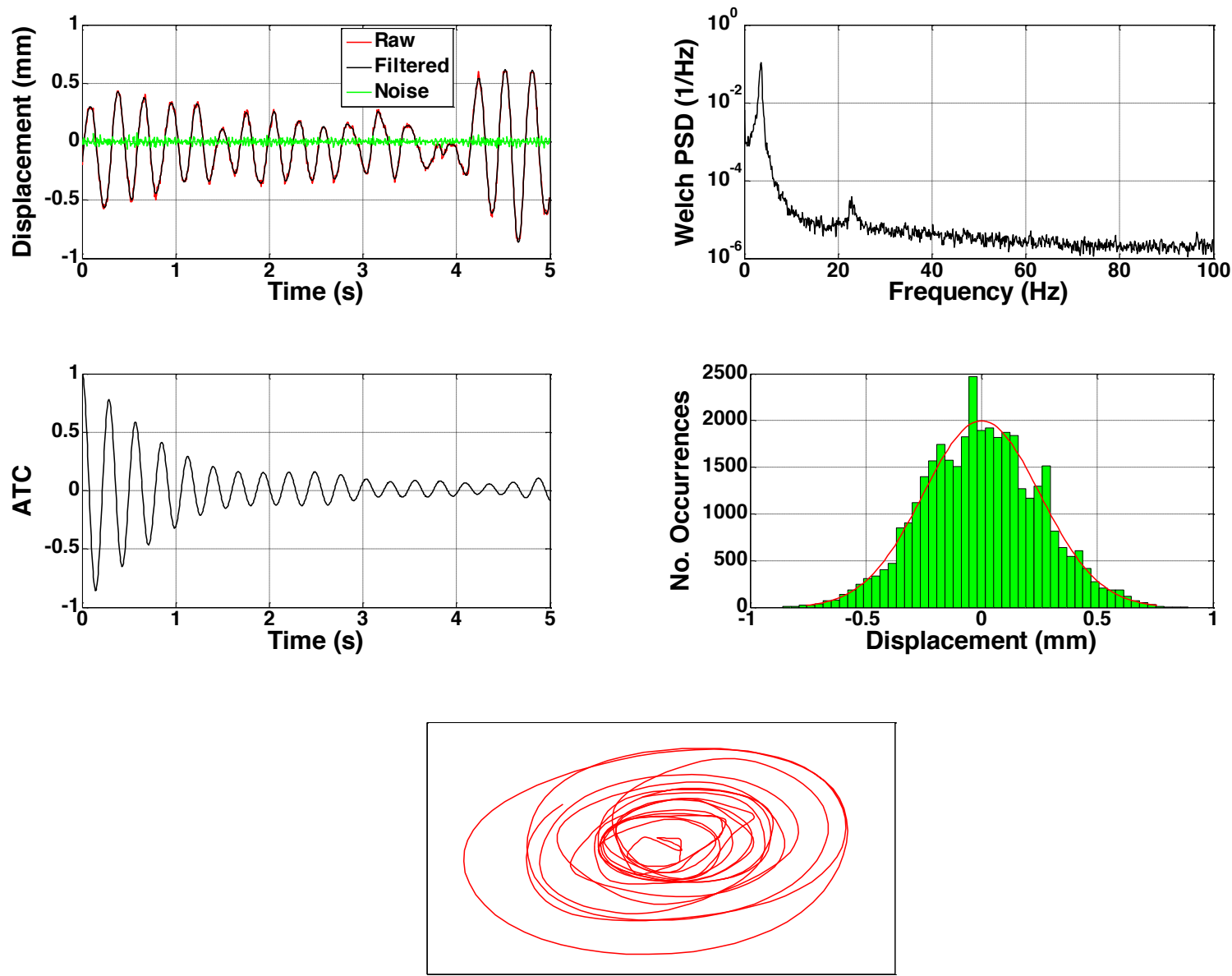

Fig. 10. Flow-induced vibration of the blunt-end rod at high flow velocity $\left(u^{*}: 83.5 ; R e_{a n n}: 35.110^{3}\right)$. Top-Left: free-end displacement time series ( $5 \mathrm{~s}$ sample); Top-right: free-end displacement power spectrum (PSD); Middle-left: free-end displacement autocorrelation function (ATC); Middle-right: free-end displacement histogram (5 s sample); Bottom: trajectory of the system in phase-space. 

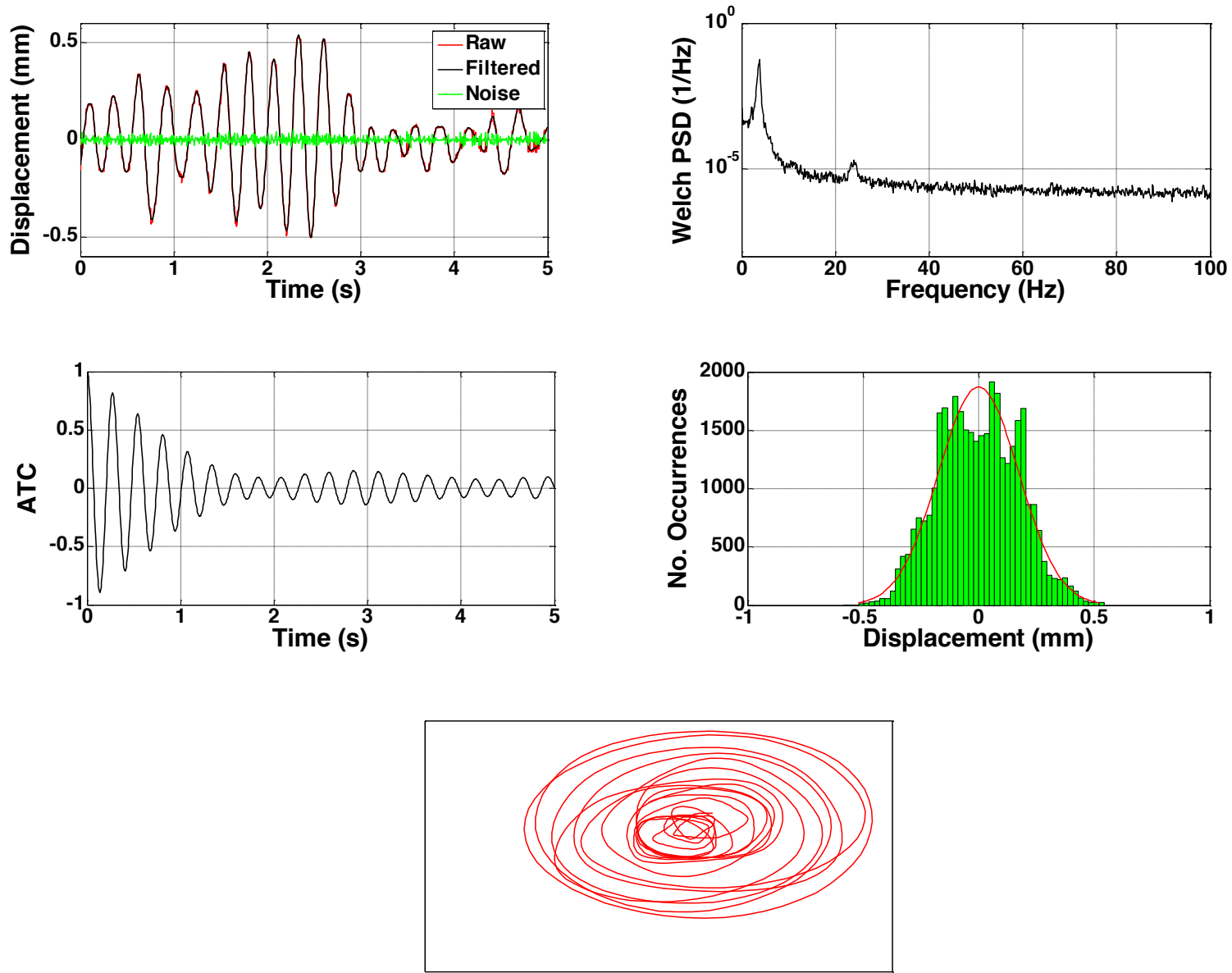

Fig. 11. Flow-induced vibration of the curved-end rod at high flow velocity $\left(u^{*}: 83.1 ; R e_{a n n}: 36.410^{3}\right)$. TopLeft: free-end displacement time series ( $5 \mathrm{~s}$ sample); Top-right: free-end displacement power spectrum (PSD); Middle-left: free-end displacement autocorrelation function (ATC); Middle-right: free-end displacement histogram (5 s sample); Bottom: trajectory of the system in phase-space. 

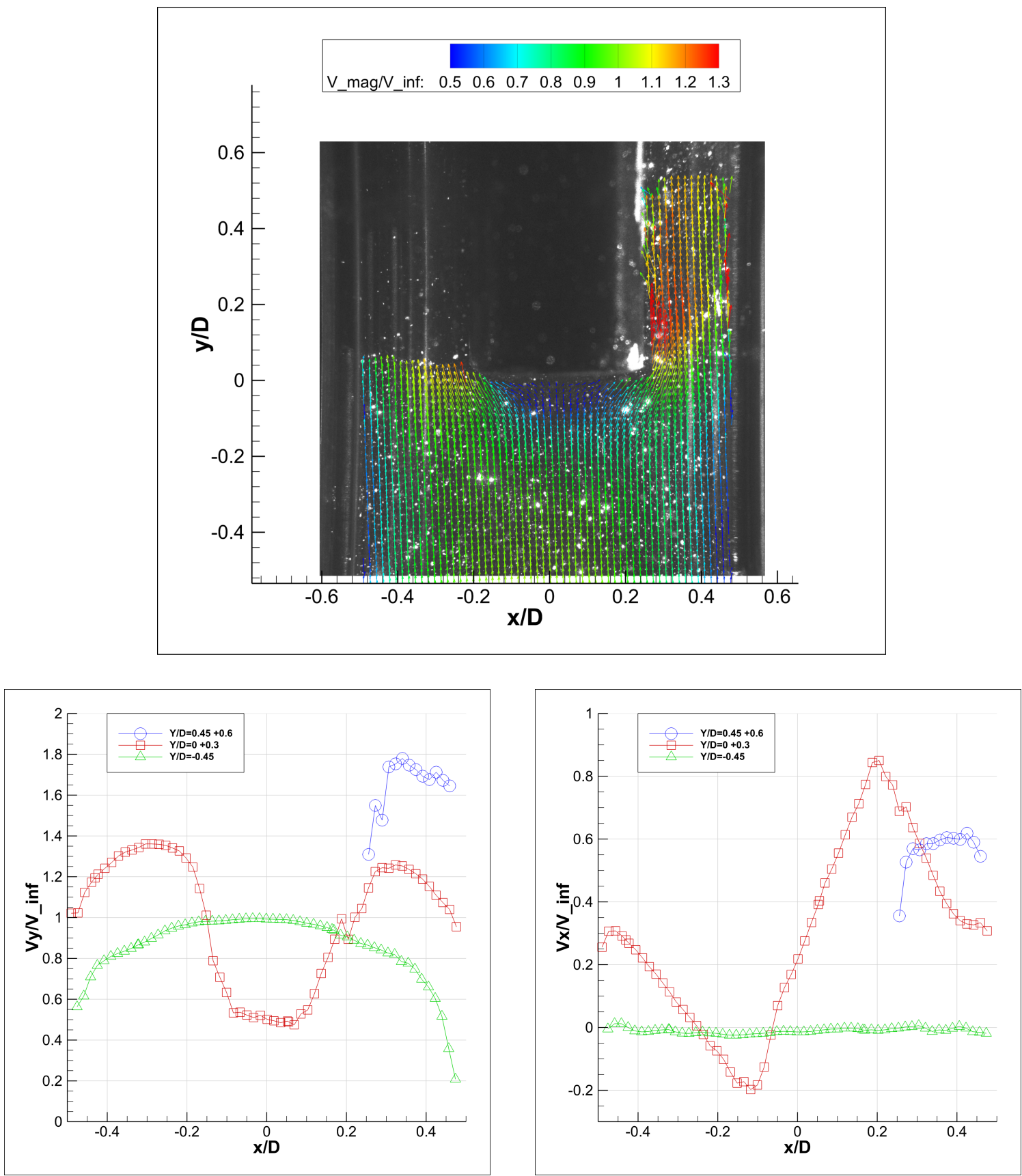

Fig. 12. Flow visualization of the blunt-end rod at low flow velocity $\left(u^{*}: 35.7 ; R e_{a n n}: 16.410^{3} ; \mathrm{V}_{-}\right.$inf: $1.3 \mathrm{~m} \mathrm{~s}^{-}$ ${ }^{1}$ ). Top: velocity vector field; Bottom-left: axial (vertical) velocity profiles; Bottom-right: radial (horizontal) velocity profiles. 

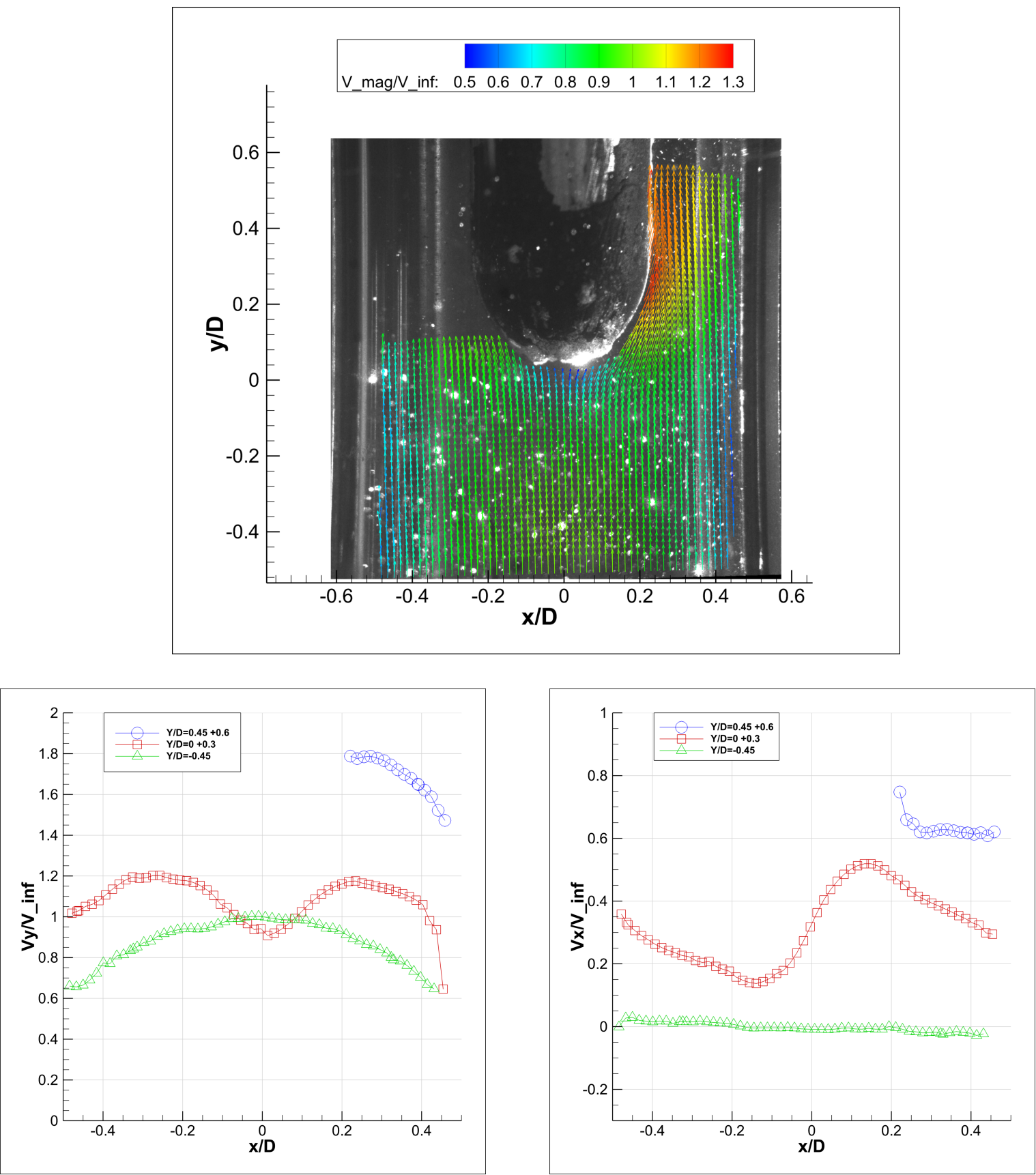

Fig. 13. Flow visualization of the curved-end rod at low flow velocity $\left(u^{*}: 35.4 ; R e_{a n n}: 16.810^{3} ; \mathrm{V} \_\right.$inf: $1.3 \mathrm{~m} \mathrm{~s}$ ${ }^{1}$ ). Top: velocity vector field; Bottom-left: axial (vertical) velocity profiles; Bottom-right: radial (horizontal) velocity profiles. 

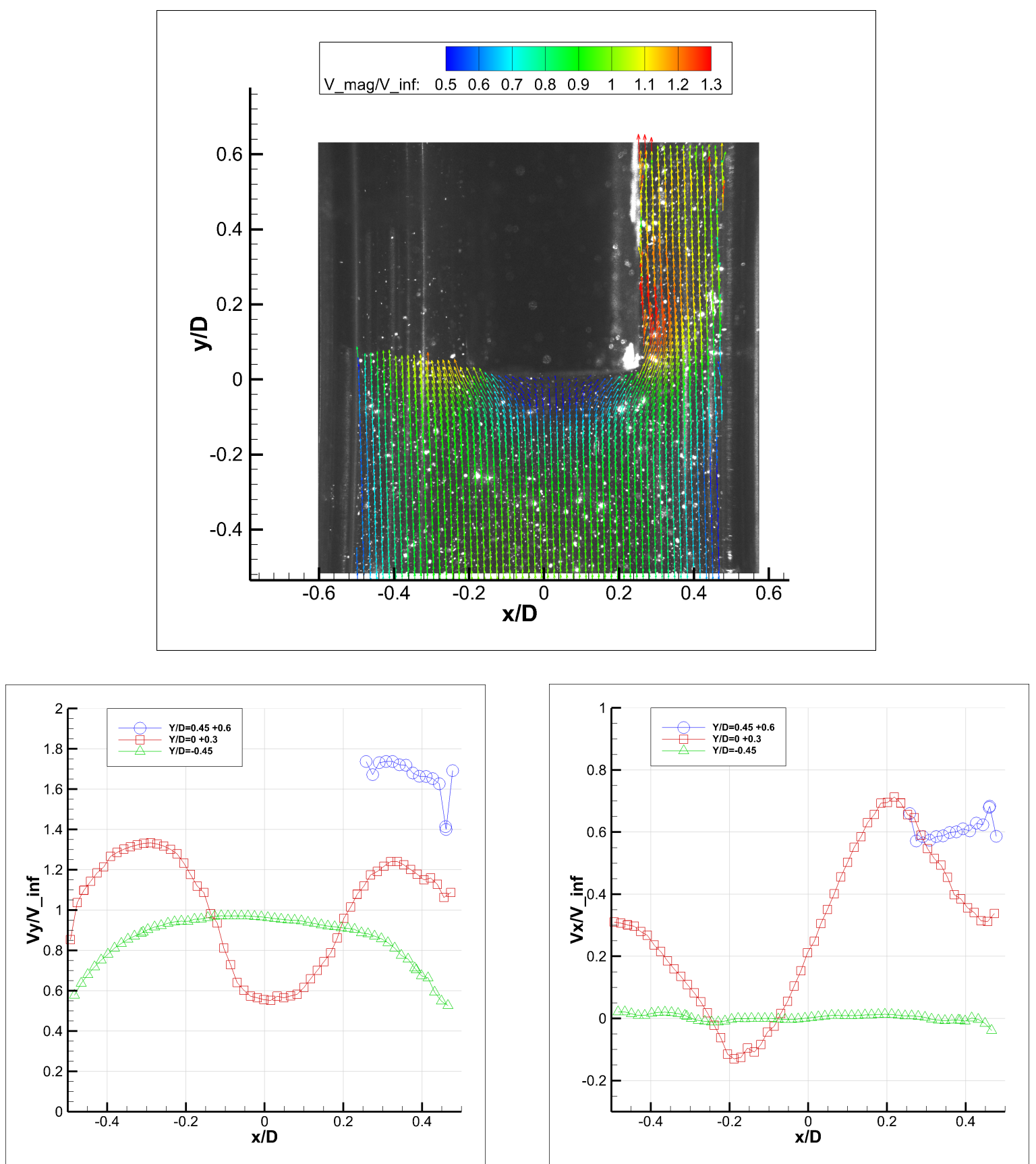

Fig. 14. Flow visualization of the blunt-end rod at high flow velocity $\left(u^{*}: 83.5 ; R e_{a n n}: 35.110^{3} ; \mathrm{V} \_\right.$inf: $3.0 \mathrm{~m} \mathrm{~s}$ ${ }^{1}$ ). Top: velocity vector field; Bottom-left: axial (vertical) velocity profiles; Bottom-right: radial (horizontal) velocity profiles. 

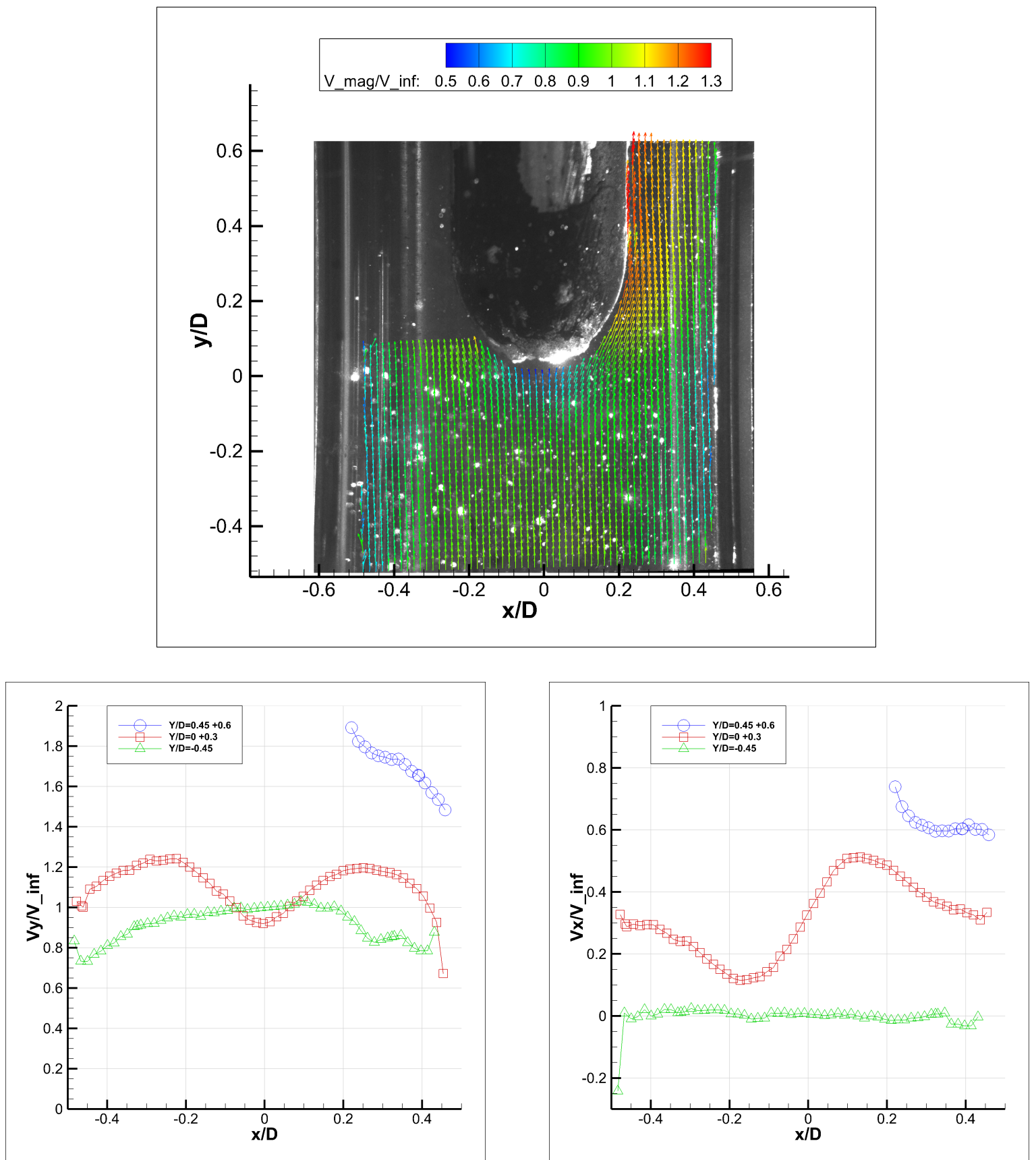

Fig. 15. Flow visualization of the curved-end rod at high flow velocity $\left(u^{*}: 83.1 ; R e_{a n n}: 36.410^{3} ; \mathrm{V}\right.$ inf: $3.0 \mathrm{~m}$ $\mathrm{s}^{-1}$ ). Top: velocity vector field; Middle: axial (vertical) velocity profiles; Bottom: radial (horizontal) velocity profiles. 
Table 1. Vibrating rods geometrical and mechanical details.

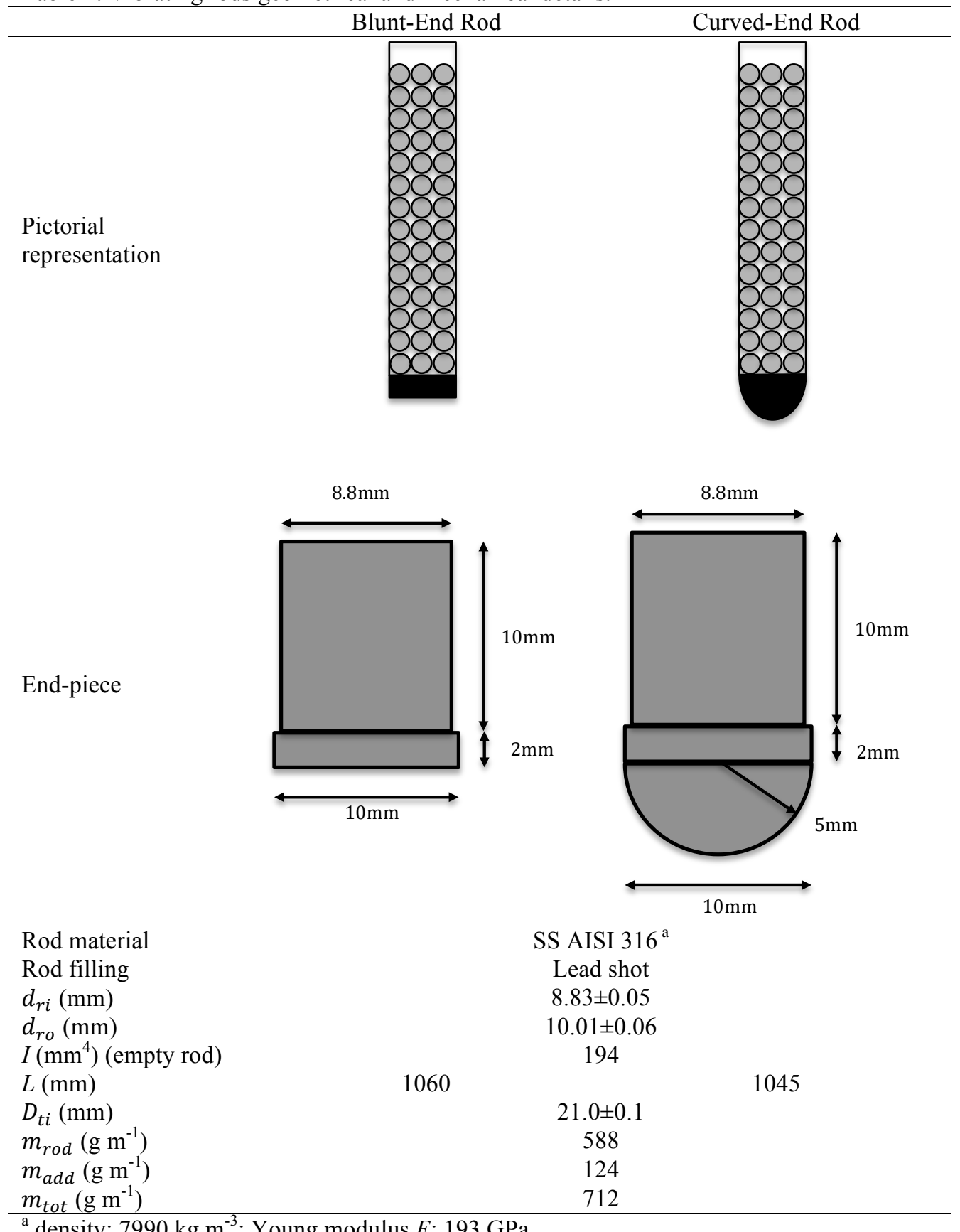

${ }^{\text {a }}$ density: $7990 \mathrm{~kg} \mathrm{~m}^{-3}$; Young modulus $E: 193 \mathrm{GPa}$

Table 2. Frequencies and damping ratios for free vibration tests.

\begin{tabular}{lcc}
\hline & Blunt-End Rod & Curved-End Rod \\
\hline$f_{0}(\mathrm{~Hz})$ & $3.7 \pm 0.1$ & $3.8 \pm 0.1$ \\
$f_{\text {pred }}(\mathrm{Hz})$ from Eq. (1) & 3.6 & 3.7 \\
$\zeta_{0}$ & $(1.4 \pm 0.1) 10^{-2}$ & $(1.3 \pm 0.1) 10^{-2}$ \\
$\zeta_{\text {pred }}$ from Eq. (4) & $1.210^{-2}$ & $1.210^{-2}$ \\
\hline
\end{tabular}

